\title{
Analisis Tingkat Kepuasan Mutu Pelayanan Badan Penyelenggara Jaminan Sosial (BPJS) di RSUD Kota Madya Langsa dengan Model Service Quality (SERVQUAL)
}

\author{
Roy Sari Milda Siregar ${ }^{1}$, Petri Yusrina ${ }^{2}$, Rica Yunita ${ }^{3}$ \\ 1,2,3 Dosen Universitas Ubiudiyah, Banda Aceh \\ ${ }^{1}$ roy.sari.milda@gmail.com, ${ }^{2}$ ie_febrina@yahoo.com, ${ }^{3}$ yoeni_ika2@yahoo.co.id
}

\begin{abstract}
Analysis of the work program of BPJS can be utilized to determine the applicability of the program to fulfil the needs of the patients as the direct beneficiary of the program. This study is intended to be the basis for management of BPJS, hospital and government to improve the quality of services. The research is a descriptive-qualitative field study and using SERVQUAL method that considers BPJS beneficiary satisfaction in terms of principle, Confidence, Reliability, Tangibility, Empathy and Responsiveness. A total of 30 questionnaires were distributed to the patients of BPJS from diverse educational background, occupation, age and gender. Based on the analysis, patient satisfaction with services obtained by BPJS are as follows: low satisfaction (10\%), medium $(66,7 \%)$ and high (23,3\%).
\end{abstract}

Keywords: End-user computing satisfaction, user satisfaction, evaluation of information systems.

\section{PENDAHULUAN}

Sejak awal tahun 2014, PT Askes bertransformasi menjadi BPJS. Semula PT Askes dikhususkan hanya kepada pegawai negeri atau pemerintahan. Namun, sejak program Jaminan Kesehatan Nasional (JKN) dijalankan, BPJS selaku penyelenggara JKN diberlakukan bagi seluruh masyarakat dengan iuran wajib bagi yang mampu dan subsidi bagi yang tidak mampu. Untuk mendukung programnya, BPJS diharuskan bekerja sama dengan rumah sakit-rumah sakit rekanan. Terlepas dari tujuan dan maksud baiknya, sejak awal penyelenggaran, BPJS telah menuai banyak kritik. Di antaranya mengenai proses pendaftaran yang memakan waktu, pelayanan kesehatan bagi pemegang kartu BPJS yang lambat dan setengah hati, insentif yang tidak memadai bagi dokter, alokasi pendanaan yang masih rentan akan masalah, dan juga termasuk persoalan sosialisasi yang belum memadai (mutupelayanankesehatan.net). Selain BPJS, yang juga mendapat sorotan tajam adalah pelayanan rumah sakit yang diduga melakukan diskriminasi terhadap pasien pemegang kartu BPJS. Rumah sakit sering dituding menelantarkan pasien, mengabaikan hak-hak pasien, dan perawatan yang tidak memadai hanya karena pasien adalah peserta BPJS. Oleh sebab itu, tujuan dari penelitian ini adalah untuk mengetahui keinginan dan kebutuhan pasien untuk memperbaiki kualitas pelayanan RSUD Langsa terkait penerapan BPJS.

Paradigma filosofi yang digunakan dalam penelitian ini adalah Quality Function Deployment (QFD) atau penyebaran fungsi mutu yang merupakan alat yang digunakan untuk mendukung penerapan TQM.Variabel yang diukur adalah Prinsip, Keyakinan, Keandalan, Fisik Nyata, Empati dan Daya Tanggap. Hasil akhir dari penelitian ini dapat menjadi acuan perbaikan dan peningkatan kualitas pelayanan pasien BPJS di rumah sakit rekanan 


\section{METODE PENELITIAN}

Dalam setiap penelitian dibutuhkan sebuah dasar yang kuat. Referensi yang paling tepat adalah dengan studi literatur sebanyak-banyaknya materi yang terkait dengan penelitian dan memahami pelbagai penelitian serupa yang pernah dilakukan oleh penelitipeneliti sebelumnya. Penelitian dengan menggunakan metode Servqual pernah dilakukan oleh Paramita, dkk dalam jurnal yang berjudul "Penilaian Kepuasan Konsumen Terhadap Kualitas Pelayanan Menggunakan Metode Servqual (Serice Quality) dan Six Sigma (Studi Kasus Pada "Restoran Dahlia” Pasuruan)”. Dalam penelitian tersebut diperoleh yang menjadi prioritas perbaikan adalah atribut A3 (kesesuaian kualitas produk dan jasa terhadap harga yang ditetapkan), sehingga perlu diperbaiki dari sisi manusia, material, metode, mesin serta modal[1].

Metode Servqual juga dilakukan oleh penelitian sebelumnya yang dilakukan oleh Sugianto, dkk dalam jurnalnya dijelaskan mengenai apakah service quality, food quality dan price memiliki pengaruh terhadap kepuasan pelanggan/konsumen dari Restoran Yung Ho Surabaya. Hasil penelitian ini menunjukkan bahwa keenam variabel Service Quality, Food Quality dan Price berpengaruh signifikan terhadap kepuasan pelanggan. Adapun faktor yang paling dominan adalah Service Quality[3].

Penelitian yang ikut mengangkat metode servqual adalah penelitian yang dilakukan oleh Parwati, Niken dan Nugorho, Yoga, Arif (2013). Analisis Kualitas Pelayanan Pada Rumah Sakit Ibu dan Anak XYZ. Pada hasil penelitian, diketahui bahwa nilai gap masih negatif, yang artinya pasien masih belum puas dengan pelayanan rumah sakit dan membutuhkan perbaikan di lima variabel yaitu tangible, responsive, reliable, assurance dan empathy[2].

\subsection{Model Service Quality (Servqual)[4]}

Definisi kepuasan pelanggan adalah persepsi pelanggan terhadap suatu pelayanan yang didapatkannya. Kualitas jasa memiliki lima dimensi dasar. Jasa yang diharapkan (expected services) dan jasa yang dirasakan (perseived service) memiliki dimensi yang sama. Dimensi ini dinilai sewaktu pelanggan diminta untuk menyatakan expected dan perseived services yang diterimanya. Dimensi kualitas jasa tersebut adalah :

1. Bukti langsung (tangibles), meliputi fasilitas fisik, perlengkapan, karyawan dan sarana komunikasi

2. Keandalan (reliability), yaitu kemampuan untuk memberikan pelayanan yang dijanjikan dengan segera, akurat dan memuaskan.

3. Daya tanggap (responsiveness), yaitu respon atau kesigapan karyawan dalam membantu pelanggan dan memberikan pelayanan yang cepat dan tanggap, yang meliputi kesigapan karyawan dalam melayani pelanggan, kecepatan karyawan dalam menangani transaksi, dan penanganan keluhan pelanggan.

4. Jaminan (assurance), meliputi kemampuan karyawan atas pengetahuan terhadap produk secara tepat, kualitas keramah-tamahan, perhatian dan kesopanan dalam memberikan pelayanan, keterampilan dalam memberikan informasi, kemampuan dalam memberikan di dalam memanfaatkan jasa yang ditawarkan, dan kemampuan dalam menentukan kepercayaan pelanggan terhadap perusahaan.

Dimensi jaminan ini merupakan gabungan dari dimensi :

a. Kompetensi (competency), artinya keterampilan dan pengetahuan yang dimiliki oleh karyawan untuk melakukan pelayanan

b. Kesopanan (courtesy), yang meliputi keramahan, perhatian, dan sikap para karyawan

c. Kredibilitas (credibility), meliputi hal-hal yang berhubungan dengan kepercayaan kepada perusahaan, seperti reputasi, prestasi, dan sebagainya.

5. Empati (empathy), yaitu perhatian secara individual secara individual yang diberikan perusahaan kepada pelanggan, seperti kemudahan untuk menghubungi perusahaan, 
kemampuan karyawan untuk berkomunikasi dengan pelanggan, dan usaha perusahaan untuk memahami keinginan dan kebutuhan pelanggannya.

Dimensi empati ini merupakan gabungan dari dimensi :

a. Akses (access), meliputi kemudahan untuk memanfaatkan jasa yang ditawarkan perusahaan.

b. Komunikasi (communication), merupakan kemampuan melakukan komunikasi untuk menyampaikan informasi kepada pelanggan atau memperoleh masukan dari pelanggan.

c. Pemahaman pada pelanggan (understanding the customer), meliputi usaha perusahaan utnuk mengetahui dan memahami kebutuhan dan keinginan pelanggan.

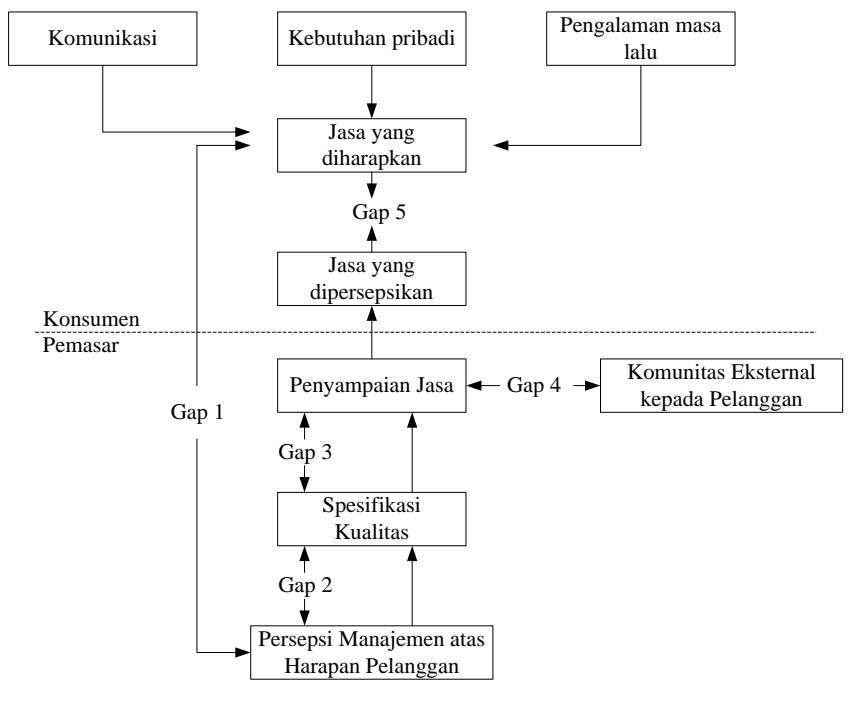

Gambar 1. Model Konseptual Kualitas Jasa Servqual

\subsection{Evaluasi dengan metode Servqual}

Berdasarkan evaluasi yang dilakukan, dapat dibuat ke dalam bentuk penilaian dan implikasi Servqual sebagai berikut:

\subsubsection{Variabel Compliance}

Pada pertanyaan apakah BPJS memberikan fasilitas sesuai dengan hak peserta, sebanyak $76 \%$ responden merasa Puas, sedangkan mengenai sosialisasi produk, haya $50 \%$ yang sudah merasa cukup mengetahui informasi tersebut. Sementara itu untuk pertanyaan apakah BPJS memberikan pertanggungjawaban terhadap layanan yang diterima, 60\% menjawab Puas.

\subsubsection{Variabel Assurance}

Untuk menilai variabel Assurance, diberikan tiga pertanyaan, yaitu yang berkenaan dengan kejelasan pemaparan produk dan fasilitas yang akan diterima (tingkat kepuasan 58\%), pengetahuan karyawan BPJS dan Rumah Sakit tentang BPJS (tingkat kepuasan 76,6\%) dan keterampilan karyawan, dokter, perawat dalam menangani keluhan pasien BPJS (tingkat kepuasan 70,6\%).

\subsubsection{Variabel Realibility}

Untuk mengukur tingkat realibilitas, diberikan tiga pertanyaan yaitu mengenai: Kemudahan pasien dalam mengakses fasilitas sesuai haknya, Ketepatan dan kecepatan 
waktu operasional dalam melayani, dan Penawaran Produk BPJS kepada peserta baru dan lama dengan tingkat kepuasan masing-masing adalah 70,7\%, 59,3\% dan 46,7\% (di bawah yang diharapkan).

\subsubsection{Variabel Tangibles}

Ukuran dari variabel ini adalah apakah pasien telah cukup puas dengan fasilitas rumah sakit, Kebersihan dan Kerapian, serta Peletakan Brosur dan pengumuman mengenai BPJS, di mana tingkat kepuasan dari pasien terhadap pertanyaan-pertanyaan tersebut adalah masing-masing: 68\%, 77,3\%, dan 50\%.

\subsubsection{Variabel Empathy}

Untuk mengukur tingkat kepuasan pada variabel Empathy adalah dengan memberikan tiga pertanyaan yang berkaitan dengan perasaan yang dirasakan oleh pasien mengenai apakah pihak BPJS dan Rumah Sakit: Memberikan perhatian kepada pasien BPJS (tingkat kepuasan 74,7\%), Keramahan dan Kesopanan Karyawan, Dokter dan Perawat dalam melayani (tingkat kepuasan 67,3\%) dan Pelayanan yang adil ke setiap pasien baik BPJS maupun Umum (tingkat kepuasan 72\%).

\subsubsection{Variabel Responsiveness}

Tingkat kepuasan terhadap Variabel Responsiveness ini diukur dengan memberikan pertanyaan seputar kemampuan rumah sakit dalam menanggapi masalah pasien BPJS (tingkat kepuasan sebesar 71,3\%), Kemampuan karyawan RS dalam berkomunikasi dengan pasien BPJS (tingkat kepuasan sebesar 69,3\%), dan Kemampuan karyawan BPJS dan tenaga medis dalam menanggapi keluhan pasien (tingkat kepuasan $58 \%)$.

Dari keenam variabel, dilakukan perbandingan skor faktual dengan skor hipotetik guna mencari persentasi kepuasan pengguna terhadap sistem dibandingkan dengan kepuasan yang diharapkan. Hasilnya dapat dilihat pada gambar 2 sebagai berikut.

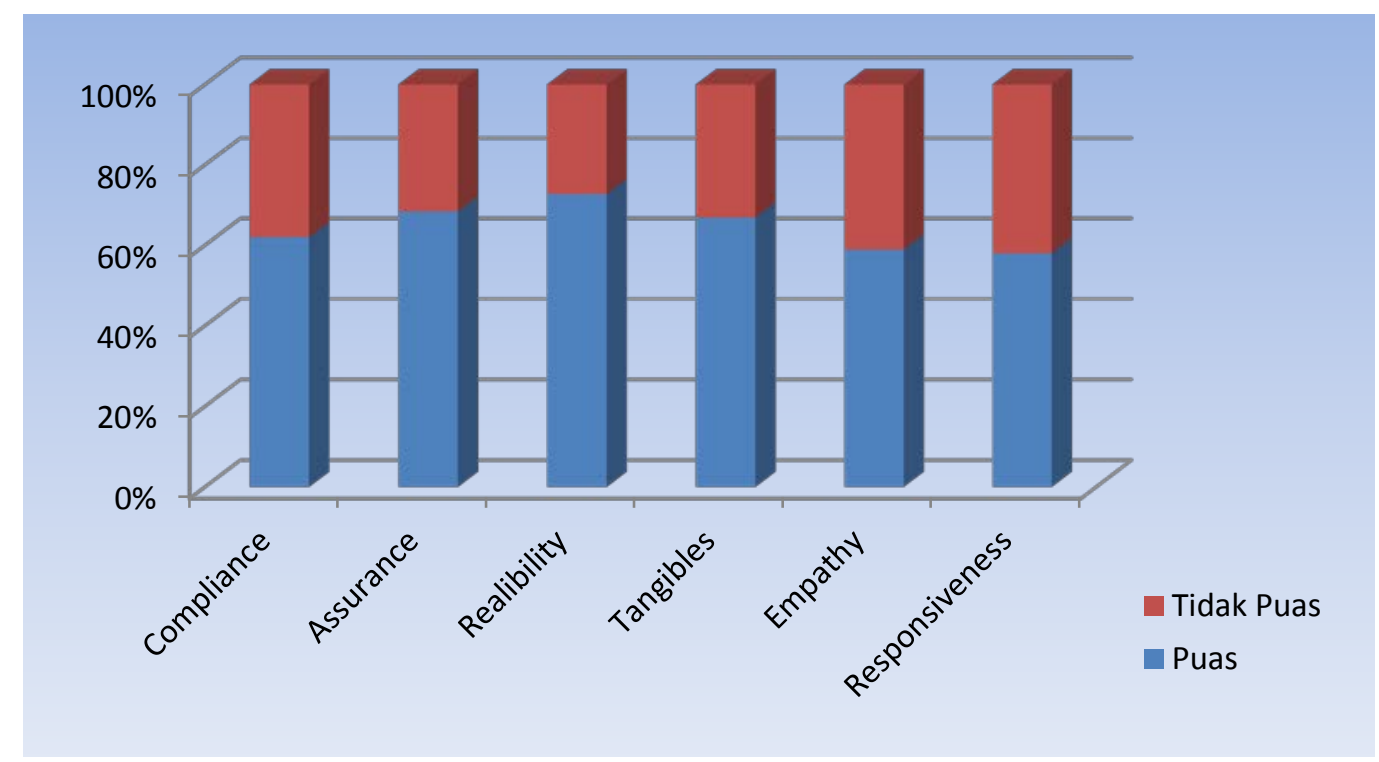

Gambar 2. Nilai Tingkat Kepuasan Variabel Servqual.

Dari grafik dapat dilihat perbandingan keenam variabel. Nilai-nilai sangat beragam. Nilai yang tertinggi adalah sebesar $72,7 \%$ yaitu untuk nilai variabel Realibility. Sedangkan untuk variabel lainnya nilainya antara 50\% sampai dengan $70 \%$. Lebih rinci dapat dijabarkan: Compliance (62\%), Assurance (68\%), Realibility (72,7\%), Tangibles (66,9\%), Empathy (58,9\%), dan Responsiveness (58\%). 
Untuk mencari nilai klasifikasi evaluatif diperlukan nilai mean dan stardar deviasi yang dapat dilihat pada tabel hasil perhitungan dengan aplikasi SPSS berikut.

Tabel 1. Nilai Descriptive Statistics.

\begin{tabular}{|c|r|r|r|r|r|}
\hline & \multicolumn{1}{|c|}{ N } & Minimum & Maximum & Mean & Std. Deviation \\
\hline VAR00001 & 30 & 43.00 & 72.00 & 58.8000 & 8.74702 \\
Valid N (listwise) & 30 & & & & \\
\hline
\end{tabular}

Dengan demikian dapat ditentukan klasifikasi evaluatif seperti tabel di bawah ini.

Tabel 2. Nilai Klasifikasi Evaluatif Variabel Servqual.

\begin{tabular}{|c|c|c|c|c|}
\hline Klasifikasi & $\begin{array}{c}\text { Norma } \\
\text { Klasifikasi }\end{array}$ & Skor & Frekuensi & Persen \\
\hline Rendah & $X \leq \mu-1 \sigma$ & $\mathrm{X} \leq 50,1$ & 3 & 10 \\
\hline Sedang & $\begin{array}{c}\mu-1 \sigma<\mathrm{X}<\mu+ \\
1 \sigma\end{array}$ & $50,1<X<67,5$ & 20 & 66,7 \\
\hline Tinggi & $\mathrm{X}>\mu+1 \sigma$ & $X>67,5$ & 7 & 23,3 \\
\hline Total & & & 30 & 100 \\
\hline
\end{tabular}

Klasifikasi Evaluatif keenam variabel Servqual dapat dilihat pada gambar di bawah ini:

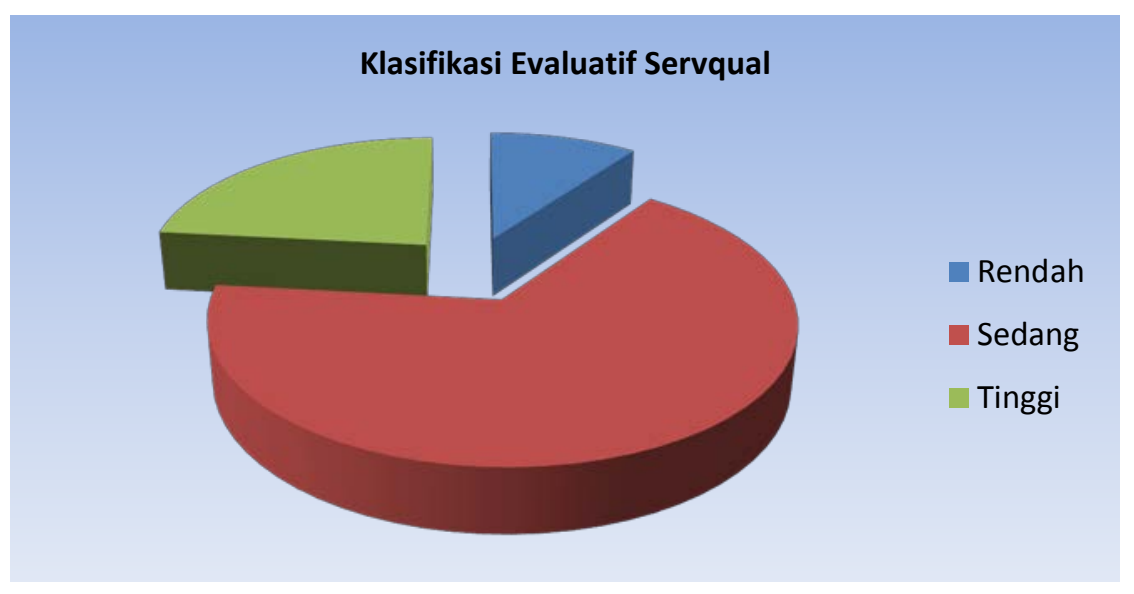

Gambar 3. Klasifikasi Evaluatif Variabel Servqual.

Pada gambar di atas dapat dilihat bahwa tingkat kepuasan pasien BPJS dapat dikategorikan ke dalam tiga tingkatan yaitu Rendah, Sedang dan Tinggi. Berdasarkan perhitungan, maka tingkat Kepuasan Rendah diperoleh sebesar 10\%, Kepuasan Sedang sebesar 66,77\% dan Kepuasan Tinggi sebesar 23,3\%.

Dengan cara membandingkan skor hipotetik dan real, didapat perbandingan tingkat kepuasan total 65,3 \% dari nilai kepuasan yang seharusnya yaitu sebesar 100\%. Lebih jelas dapat dilihat perbandingannya pada diagram di bawah ini. 


\section{Tingkat Kepuasan Pasien BPJS Terhadap Program BPJS}

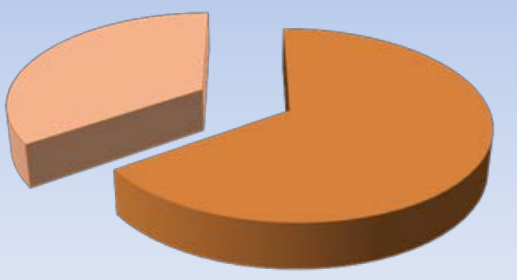

Gambar 4. Tingkat Kepuasan Pasien BPJS Terhadap Program BPJS di RSUD Langsa.

\section{KESIMPULAN}

Berdasarkan uraian yang telah dijabarkan pada bagian sebelumnya, maka dapat disimpulkan sebagai berikut:

d. Pada tiap variabel pengukuran, tingkat kepuasan paling tinggi adalah terhadap variabel Realibility, artinya pasien sudah cukup puas dengan kemudahan pasien akan akses terhadap fasilitas, ketepatan dan kecepatan, dan penawaran produknya. Adapun untuk variabel lainnya masih berada dalam kisaran 50-70\% dan masih perlu ditingkatkan.

e. Secara klasifikasi evaluatif, diperoleh kepuasan rendah sebesar $10 \%$,kepuasan sedang $66,7 \%$ dan kepuasan tinggi sebesar 23,3\%. Tentunya hal ini masih dapat ditingkatkan lagi agar semakin banyak pasien yang merasa puas terhadap pelayanan BPJS.

f. Secara keseluruhan, sistem dan pelayanan BPJS telah mencapai tingkat kepuasan 65,3\% di mana seharusnya dapat ditingkatkan lagi di kemudian hari hingga lebih mendekati nilai maksimum yaitu 100\% dengan menguatkan setiap variabel yang telah dijabarkan dalam penelitian ini.

\section{DAFTAR PUSTAKA}

[1] Paramita, Santya, Meryana, dkk. (2014).Penilaian Kepuasan Konsumen Terhadap Kualitas Pelayanan Menggunakan Metode Servqual (Service Quality) dan Six Sigma (Studi Kasus Pada "Restoran Dahlia” Pasuruan). Jurnal Keuangan dan Bisnis 4(2): 148-159. skripsitip.staff.ub.ac.id/files/2014/06/Jurnal-MeryanaSantya-P.pdf.diakses 5 November 2016

[2] Sugianto Jimmy., Sugiharto, Sugiono.(2013). Analisa Pengaruh Service Quality, Food Quality, dan Price Quality Terhadap Kepuasan Pelanggan di Restoran Yung Ho Surabaya. Jurnal Manajemen Pemasaran Petra Vol 1, No.2, (2013), hal 1-10. studentjournal.petra.ac.id/index.php/manajemen-pemasaran/.../786. Diakses 5 November 2016.

[3] Parwati, Niken dan Nugroho, Yoga, Arif (2013). Analisis Kualitas Pelayanan Pada Rumah Sakit Ibu dan Anak XYZ. Jurnal Ilmiah Teknik Industri (2013), Vol.1, No.1, hal 38-45

[4] Valerie A Zeithaml,dkk. Delivering Quality. Free Press. New York. 1990. hal. 2345 